\title{
Broadband Fourier domain mode-locked laser for optical coherence tomography at $1060 \mathrm{~nm}$
}

Marschall, Sebastian; Klein, Thomas; Wieser, Wolfgang; Biedermann, Benjamin; Pedersen, Christian; Huber, Robert; Andersen, Peter E.

Published in:

Proceedings of Optical Sensors and Biophotonics III

Publication date:

2011

Link back to DTU Orbit

Citation (APA):

Marschall, S., Klein, T., Wieser, W., Biedermann, B., Pedersen, C., Huber, R., \& Andersen, P. E. (2011).

Broadband Fourier domain mode-locked laser for optical coherence tomography at $1060 \mathrm{~nm}$. In Proceedings of Optical Sensors and Biophotonics III http://www.acp-ce.org/index.html

\section{General rights}

Copyright and moral rights for the publications made accessible in the public portal are retained by the authors and/or other copyright owners and it is a condition of accessing publications that users recognise and abide by the legal requirements associated with these rights.

- Users may download and print one copy of any publication from the public portal for the purpose of private study or research.

- You may not further distribute the material or use it for any profit-making activity or commercial gain

- You may freely distribute the URL identifying the publication in the public portal 


\title{
Broadband Fourier domain mode-locked laser for optical coherence tomography at $1060 \mathrm{~nm}$
}

\author{
Sebastian Marschall ${ }^{a}$, Thomas Klein ${ }^{b}$, Wolfgang Wieser $^{b}$, Benjamin Biedermann ${ }^{b}$, \\ Christian Pedersen ${ }^{a}$, Robert Huber $^{b}$, Peter E. Andersen ${ }^{a}$ \\ ${ }^{a}$ DTU Fotonik, Department of Photonics Engineering, Technical University of Denmark, \\ P.O. Box 49, 4000 Roskilde, Denmark; \\ ${ }^{b}$ Lehrstuhl für BioMolekulare Optik, Ludwig-Maximilians-Universität München, \\ Oettingenstr. 67, 80538 München, Germany;
}

\section{INTRODUCTION}

Optical coherence tomography (OCT) in the $1060 \mathrm{~nm}$ range is very interesting for imaging the human retina and the underlying layers (choroid, sclera) ${ }^{1,2}$ due to low absorption in water and good penetration through the retinal pigment epithelium. Especially, swept source OCT (SS-OCT) enables ultra-high imaging speed if an appropriate rapidly tunable light source is used. For instance, with a state-of-the-art Fourier domain mode-locked (FDML) laser, ${ }^{3}$ densely sampled 3D dataset covering a wide field of view can be acquired within a few seconds. ${ }^{4}$ The typical gain media for fast swept sources are semiconductor optical amplifiers (SOAs) which feature fast gain dynamics enabling rapid wavelength tuning and a broad tuning bandwidth. These factors are important for OCT in order to achieve high imaging speeds and good depth resolution.

Whereas SOAs for the telecom bands $(1310 \mathrm{~nm}, 1550 \mathrm{~nm})$ are well developed, SOAs for the $1060 \mathrm{~nm}$ range have been lacking output power and bandwidth. So far commercially available devices enable tuning ranges up to $80 \mathrm{~nm}$ with around $15 \mathrm{~mW}$ output power. Although, one uses normally less than $2 \mathrm{~mW}$ on the eye for retinal imaging, certain system implementations can require higher power levels. E.g. buffering the light source output for multiplying the depth scan rate ${ }^{4,5}$ brings a power penalty of at least $6 \mathrm{~dB}$, and some OCT interferometers sacrifice a part of the input light in order to optimize the detection efficiency.

We have implemented an FDML laser using a new SOA featuring a broad gain bandwidth and high output power, even with a relatively low drive current. The gain spectrum is centered around $1060-1070 \mathrm{~nm}$ and coincides thus perfectly with the wavelength range of minimal water absorption, making it very interesting for retinal imaging. By modulating the SOA current during a wavelength sweep, we can optimize the output spectrum in order to improve the depth resolution. With a total sweep range of $100 \mathrm{~nm}$, we achieved a depth resolution of $8 \mu \mathrm{m}$ in air. Output power levels well above $20 \mathrm{~mW}$ are possible, and the performance is very similar for both sweep directions.

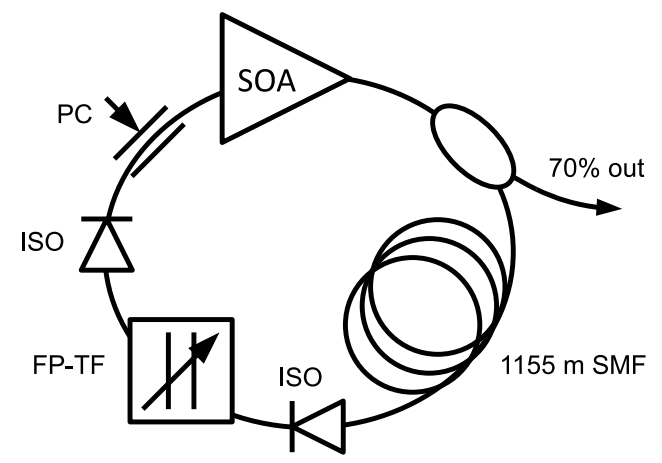

Figure 1. Schematic setup of the FDML laser. SOA: semiconductor optical amplifier, FP-TF: fiber-coupled Fabry-Perot tunable filter, SMF: single-mode fiber, ISO: optical isolator, PC: polarization controller. 

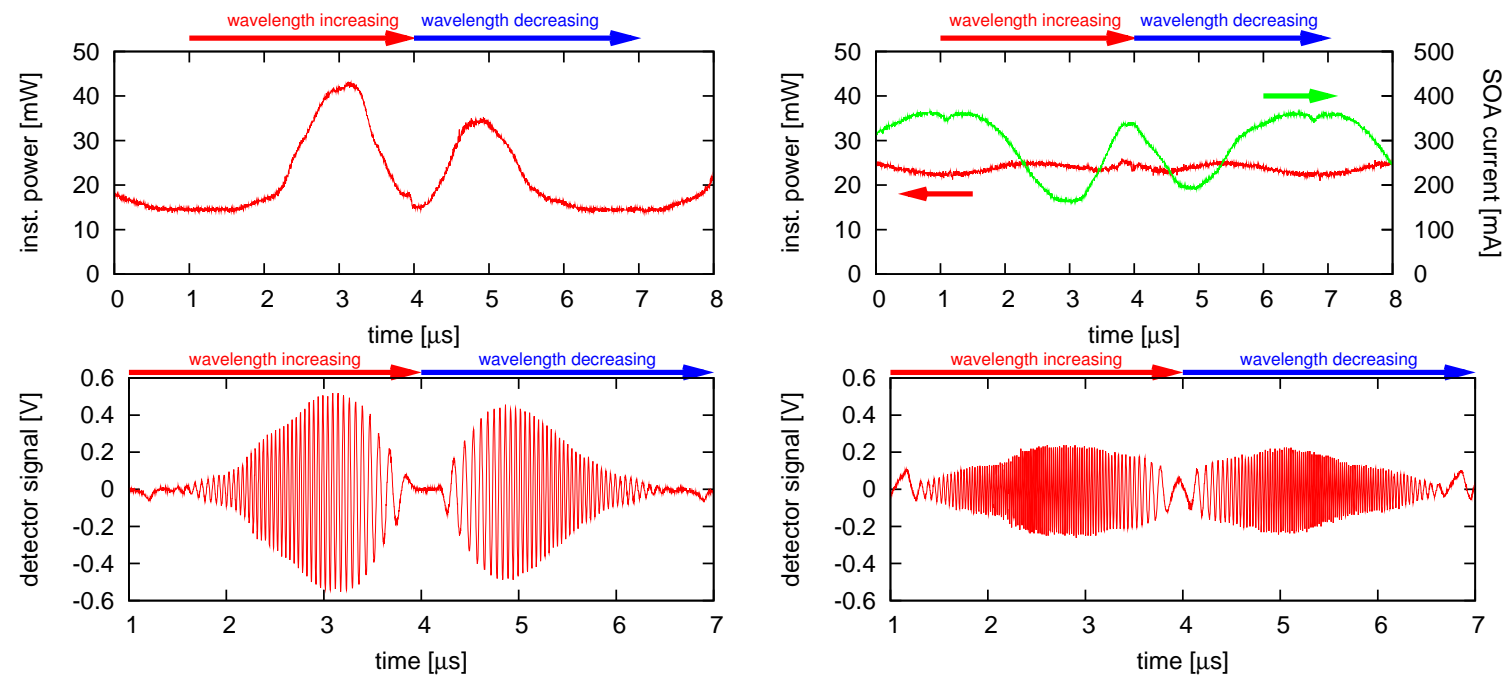

Figure 2. Top: instantaneous output power of the swept source during one sweep cycle (ca. 1-7 $\mu$ s) for $250 \mathrm{~mA}$ constant SOA current (left) and modulated SOA current (right). Bottom: corresponding exemplary interferograms from a MachZehnder interferometer.

\section{SETUP}

We tested the performance of the new SOA in an FDML laser running at $175 \mathrm{kHz}$ repetition rate (Fig. 1). $70 \%$ of the light from the SOA output are coupled out of the resonator. The remaining fraction is guided through a delay line (1155 m single-mode fiber) to a fiber-coupled Fabry-Perot tunable filter (FP-TF) which selects the wavelength that is fed back to the amplifier. Optical isolators behind and in front of the tunable filter ensure uni-directional lasing in the ring-resonator. The length of the delay line is chosen in order to match the resonator roundtrip frequency with a mechanical resonance frequency of the filter. The filter transmission linewidth is approximately $170 \mathrm{pm}$.

Using a fast SOA driver in conjunction with an arbitrary function generator, we modulated the SOA current synchronously with the wavelength sweep. By doing so, we could shape the output spectrum in order to exploit the tuning bandwidth optimally. For evaluation of the light source performance, we generated interferograms using a Mach-Zehnder interferometer with dual balanced detection and calculated the corresponding point spread functions for varying path length difference.

\section{RESULTS}

We compare the performance of the FDML laser with constant SOA current and modulated SOA current. Even with a relatively low constant current of $250 \mathrm{~mA}$, the swept source emits laser light without interruption over a sweep range of $100 \mathrm{~nm}$. The average output power is approximately $23 \mathrm{~mW}$. The instantaneous output power (Fig. 2 top left) has a high peak on the red side (longer wavelengths) and a flat tail on the blue side. The same features can be seen in the corresponding interferogram (Fig. 2 bottom left). Such a spectral shape is typical for these light sources, but not desirable, because the flat tail does not significantly improve the OCT depth resolution.

In order to optimize the depth resolution, we modulated the SOA current, and thus the optical gain during the sweep cycle, in order to achieve and output power spectrum featuring a higher baseline and a flat peak in the center (Fig. 2 top right) with the same average power $(23 \mathrm{~mW})$. The current modulation waveform was calculated by an iterative algorithm. The corresponding interferogram (Fig. 2 bottom right) shows a considerably more uniform amplitude over the entire sweep range. Accordingly, the depth resolution (defined as FWHM of the point spread functions) is $8-9 \mu \mathrm{m}$ (in air) with modulated current, and $12-13 \mu \mathrm{m}$ with constant current, although the total sweep range is $100 \mathrm{~nm}$ in both cases. The sweep spectrum extends from 1015 to $1115 \mathrm{~nm}$ and is hence well centered in the range of minimal water absorption. 

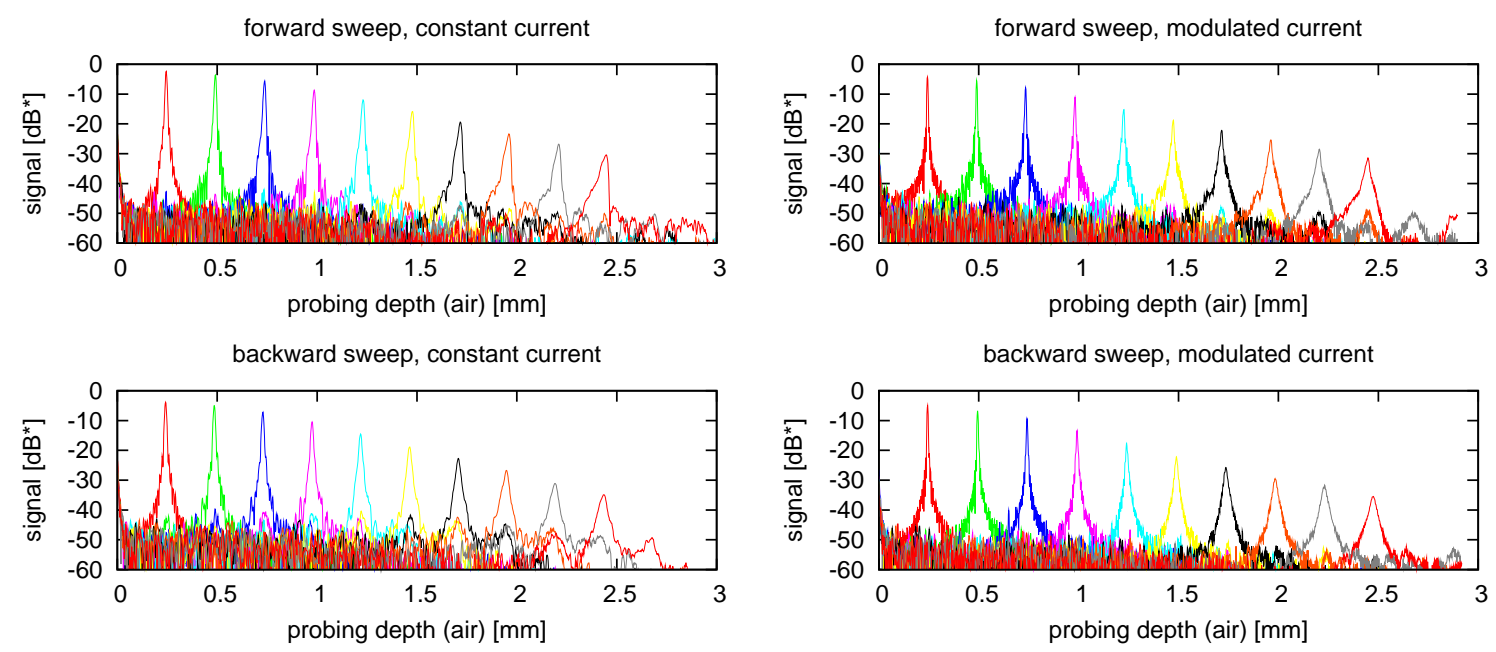

Figure 3. Point spread functions for different OCT probing depths.

Remarkably, even with constant current the interferogram amplitudes of the forward sweep (increasing wavelength) and the backward sweep (decreasing wavelength) are very similar, while they are almost symmetric with current modulation. This indicates that both sweep directions could be used for OCT imaging. The point spread functions for different interferometer delays (Fig. 3) exhibit a relatively fast signal roll-off. For constant current, the roll-off is 8.4 and $9.2 \mathrm{~dB}^{*} / \mathrm{mm}$ (forw./backw. sweep); for modulated current, it is $9 \mathrm{or} 10 \mathrm{~dB} / \mathrm{mm}$, respectively.

\section{DISCUSSION AND OUTLOOK}

Using a new SOA, we implemented an FDML swept source for the $1060 \mathrm{~nm}$ wavelength band featuring $100 \mathrm{~nm}$ sweep range and more than $20 \mathrm{~mW}$ average output power. By modulating the drive current, we optimized the spectral envelope and improved the axial resolution by $30 \%$ to $8 \mu \mathrm{m}$ in air. Both sweep directions exhibit similar performance, and might thus both be suitable for OCT imaging. In this case a depth scan rate of $350 \mathrm{kHz}$ would be possible without buffering the output. More detailed experiments are necessary to verify this hypothesis. Furthermore we will investigate in how far water absorption in the sample path affects the depth resolution of the system.

\section{REFERENCES}

1. B. Považay, K. Bizheva, B. Hermann, A. Unterhuber, H. Sattmann, A. F. Fercher, W. Drexler, C. Schubert, P. K. Ahnelt, M. Mei, R. Holzwarth, W. J. Wadsworth, J. C. Knight, and P. S. J. Russel, "Enhanced visualization of choroidal vessels using ultrahigh resolution ophthalmic OCT at $1050 \mathrm{~nm}$," Opt. Express 11(17), pp. 1980-1986, 2003.

2. Y. Yasuno, Y. Hong, S. Makita, M. Yamanari, M. Akiba, M. Miura, and T. Yatagai, "In vivo high-contrast imaging of deep posterior eye by $1-\mu \mathrm{m}$ swept source optical coherence tomography and scattering optical coherence angiography," Opt. Express 15, pp. 6121-6139, May 2007.

3. R. Huber, M. Wojtkowski, and J. G. Fujimoto, "Fourier domain mode locking (FDML): a new laser operating regime and applications for optical coherence tomography," Opt. Express 14(8), pp. 3225-3237, 2006.

4. T. Klein, W. Wieser, C. M. Eigenwillig, B. R. Biedermann, and R. Huber, "Megahertz oct for ultrawide-field retinal imaging with a $1050 \mathrm{~nm}$ fourier domain mode-locked laser," Opt. Express 19, pp. 3044-3062, Feb 2011.

5. R. Huber, D. C. Adler, and J. G. Fujimoto, "Buffered fourier domain mode locking: unidirectional swept laser sources for optical coherence tomography imaging at 370,000 lines/s," Opt. Lett. 31(20), pp. 2975-2977, 2006.

${ }^{*} \mathrm{~dB}$ is here defined as $20 \log$ of the PSF amplitude. 